\title{
XIX COLOQUIO ANUAL DE LA SOCIEDAD INTERNACIONAL PARA EL ESTUDIO DE LA FILOSOFÍA MEDIEVAL (SIEPM)
}

Se ha celebrado en Alcalá de Henares (Madrid) durante los días 18, 19 y 20 de septiembre de 2013, bajo la dirección de los Drs. Pedro Roche, de la Universidad de Alcalá, y Josep Puig, de la Universidad Complutense, el XIX Coloquio Anual de la Sociedad Internacional para el Estudio de la Filosofía Medieval, que en esta ocasión ha tenido como tema la Legitimación del poder político en el pensamiento medieval. Además de las Universidades de Alcalá y Complutense, la Sociedad de Filosofía Medieval ha colaborado en la organización del Coloquio, que ha contado con el patrocinio de diversas entidades.

Los Directores del Coloquio han estado presentes en todo momento en el mismo, pero, en el Paraninfo de la Universidad de Alcalá, bajo la presidencia de su Rector, D. Fernando Galván, fue el profesor Pedro Roche quien realizó el discurso inaugural en la mañana del día 18; en Madrid, en la sede del Centro de Estudios Políticos y Constitucionales, bajo la presidencia de su Director, D. Benigno Pendás, fue el profesor Josep Puig el encargado de pronunciar las palabras de clausura en la tarde del día 20.

Entre ambos actos se han sucedido casi treinta ponencias, que, a lo largo de la mañana y la tarde de los tres días que ha durado el Coloquio, han desarrollado prácticamente todos los aspectos del pensamiento político medieval, con referencias permanentes a la religión, la sociedad o la cultura de una época que los organizadores han querido abarcar con la mayor amplitud. Así, si un autor como Eusebio puede representar más que el pensamiento político de la Edad Media, sus antecedentes, otros como Dante y, sobre todo, Maquiavelo se puede considerar que cierran el ciclo del que se ocupan habitualmente los estudiosos del Medievo, aunque el último se sitúe cronológicamente en la Edad Moderna.

En ese panorama temporal tan amplio, se ha hecho posible el tratamiento de filósofos judíos, musulmanes y cristianos, desde Isaac Abravanel, hasta Tomás de Aquino y Juan de París, pasando por Al-Fârâbi o Ibn Khaldun y otros muchos, lo que no solo ha permitido mostrar una rica diversidad de autores sino también una variada y, con frecuencia, original fuente de problemas. Una consecuencia clara y positiva de estas múltiples aportaciones es la posibilidad de añadir a las numerosas ponencias que se centraban por sí mismas en la comparación entre autores, como las que unían el pensamiento de Eusebio con el de Pletón, o el de Palamás con el de Ockham, nuevas comparaciones entre pensadores, momentos y cuestiones que no siempre es fácil agrupar en tanta cantidad y en tan poco tiempo.

Dice mucho de la categoría alcanzada por el Coloquio y de la tarea realizada por sus organizadores, la presencia entre los participantes de nombres de estudiosos que llevan años haciendo aportaciones al pensamiento medieval que gozan de gran reconocimiento. No es fácil reunir en tres días a prestigiosos investigadores del período, venidos de diferentes continentes, como los profesores M. Arfa, F. Bertelloni, A. Black, Ch. E. Butterworth, A. Melamed, J. Miethke o G. Piaia por citar algunos ejemplos.

Otros muchos ponentes completaban el cuadro del Coloquio. En un conjunto tan heterogéneo es evidente que no todas las intervenciones han tenido la misma calidad, pero si a la señalada diversidad de temas, períodos y autores tratados, se une la presencia de especialistas 
de todo el mundo, hábil y trabajosamente seleccionados y reunidos por los organizadores, y los debates que han seguido a las intervenciones, se debe concluir que el Coloquio ha cumplido los objetivos perseguidos: servir de estímulo para generar nuevos conocimientos sobre el pensamiento político medieval, darlos a conocer en un mismo lugar y en un breve espacio de tiempo, debatir sobre los mismos y difundirlos a un público más amplio que el de los especialistas. Buena prueba de ello es que, a pesar del alto nivel de las intervenciones, no ha dejado de haber una asistencia de público que no siempre se siente atraído por reuniones científicas tan especializadas ni es fácil que haga un seguimiento tan serio como el registrado.

Hay motivo para felicitar a los organizadores por lo hecho, pero si, además, como pretenden en un futuro inmediato, se publican los resultados, la satisfacción por la utilidad de la obra resultante estará más justificada que nunca.

Francisco Castilla Urbano

Universidad de Alcalá de Henares 